\title{
Timing and duration of mare volcanism in the central region of the northern farside of the Moon
}

\author{
Tomokatsu Morota $^{1}$, Junichi Haruyama ${ }^{1}$, Makiko Ohtake $^{1}$, Tsuneo Matsunaga ${ }^{2}$, Taichi Kawamura ${ }^{1}$, Yasuhiro Yokota ${ }^{2}$, \\ Chikatoshi Honda ${ }^{3}$, Jun Kimura ${ }^{4}$, Naru Hirata ${ }^{3}$, Hirohide Demura ${ }^{3}$, Akira Iwasaki ${ }^{5}$, \\ Takamitsu Sugihara $^{6}$, and LISM Working Group

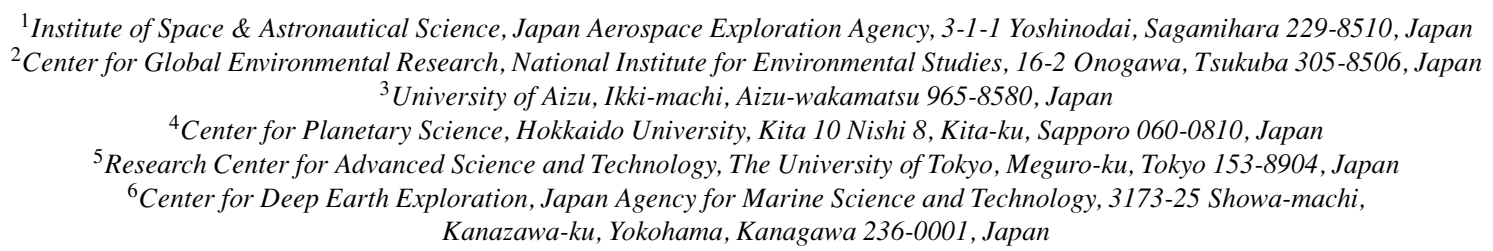

(Received August 19, 2009; Revised January 25, 2010; Accepted February 22, 2010; Online published February 21, 2011)

\begin{abstract}
Age determinations of lunar mare basalts are essential for understanding the thermal evolution of the Moon. In this study, we performed new crater size-frequency measurements in mare deposits in the central region of the northern farside, consisting of Lacus Luxuriae, Buys-Ballot, Campbell, and Kohlschütter, using high-resolution images obtained by SELENE (Kaguya) Terrain Camera. The estimated model ages of the mare deposits range from 2.7 to $3.5 \mathrm{Ga}$. On the basis of model ages for all investigated mare deposits in the central part of the northern farside, considering the results of previous studies, we concluded that mare volcanism in this region began at least as early as $3.9 \mathrm{Ga}$ and continued until $\sim 2.6 \mathrm{Ga}$. From a comparison of model ages in the region and the South Pole-Aitken basin, we found that mare volcanism in these regions ended at the same time, suggesting that the South Pole-Aitken basin formation impact had a minor effect on mare volcanism in the region.

Key words: Moon, mare volcanism, lunar farside, Feldspathic Highland Terrane, the South Pole-Aitken basin, crater size-frequency measurement.
\end{abstract}

\section{Introduction}

Unraveling the volcanic history of the Moon is essential for understanding its origin and thermal evolution. Lunar mare basalts, which are the most common volcanic features on the Moon, cover $17 \%$ of its total surface area and occur preferentially in topographic lows on the nearside (e.g., Head, 1975; Head and Wilson, 1992). On the farside, limited numbers of maria occur in some basins and craters. The asymmetrical distribution of exposed mare basalts has evoked many questions concerning the generation and emplacement mechanisms of mare basalts (e.g., Solomon, 1975; Wasson and Warren, 1980; Head and Wilson, 1992; Zhong et al., 2000; Werner and Loper, 2002). To reconstruct and understand the mechanisms, it is critical to determine the ages, volumes, and compositions of mare basalts.

A considerable number of nearside maria have been dated by using image data from Lunar Orbiters and Apollo missions (e.g., Wilhelms and McCauley, 1971; Boyce, 1976; Wilhelms, 1987; Hiesinger et al., 2000, 2003, 2006, 2008; Bugiolacchi and Guest, 2008). These studies revealed that the largest number of mare basalts formed in the Late Imbrian Epoch at 3.2 to $3.8 \mathrm{Ga}$, indicating good

Copyright (C) The Society of Geomagnetism and Earth, Planetary and Space Sciences (SGEPSS); The Seismological Society of Japan; The Volcanological Society of Japan; The Geodetic Society of Japan; The Japanese Society for Planetary Sciences; TERRAPUB.

doi:10.5047/eps.2010.02.009 agreement with radiometric ages for returned basaltic rocks, and that mare volcanism lasted until the Eratosthenian Period (e.g., Boyce, 1976) or even until the Copernican Period (Wilhelms, 1987; Hiesinger et al., 2003, 2008), suggesting that the total duration of lunar volcanism was 1.5 to $3.0 \mathrm{Ga}$.

Prior to the SELENE (Kaguya) mission (Kato et al., 2008), accurate age determinations of most maria on the farside had not been performed because of the lack of high spatial resolution images. Therefore, a systematic, highresolution mapping of the entire lunar surface, particularly the farside, is a primary objective of the SELENE mission. The Terrain Camera (TC) onboard SELENE is a panchromatic push-broom imager with two optical heads that acquire stereo data for the entire surface of the Moon with an average resolution of $10 \mathrm{~m} /$ pixel (Haruyama et al., 2008). The TC has obtained high-resolution images of most areas of the lunar farside at solar elevation angles lower than $10^{\circ}$. Using the high-resolution images, Haruyama et al. (2009) carried out crater size-frequency measurements in farside mare deposits within the South Pole-Aitken (SPA) basin and Mare Moscoviense, and found that mare volcanism on the lunar farside lasted $\sim 2.5 \mathrm{Ga}$, longer than was previously considered.

Here we performed new crater size-frequency measurements in mare deposits in the central region of the northern farside, which had been previously undated, using new high-resolution images obtained by TC. The mare deposits 


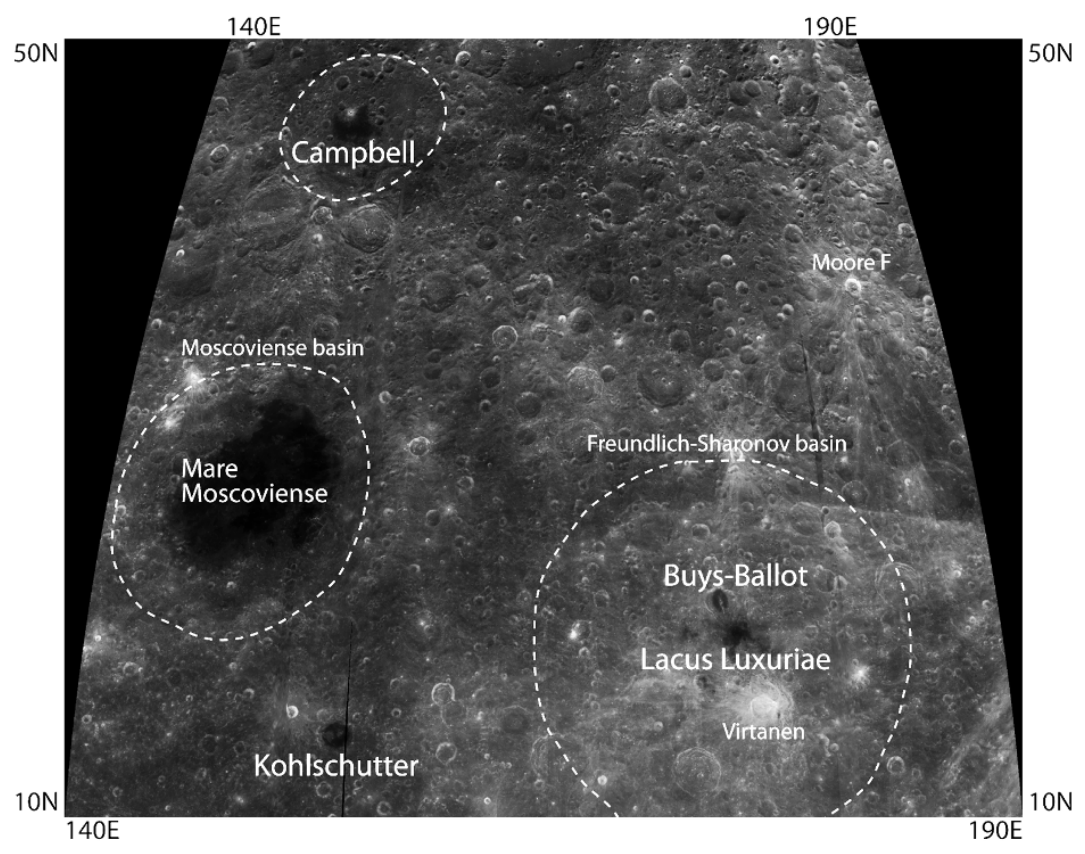

Fig. 1. Clementine $750 \mathrm{~nm}$ basemap indicating the location of the investigated mare deposits, Lacus Luxuriae, Buys-Ballot, Campbell, and Kohlschütter. Sinusoidal map projection.

include Lacus Luxuriae $\left(19^{\circ} \mathrm{N}, 176^{\circ} \mathrm{E}\right)$, and mare deposits in Buys-Ballot $\left(21^{\circ} \mathrm{N}, 175^{\circ} \mathrm{E}\right)$, Campbell $\left(45^{\circ} \mathrm{N}, 152^{\circ} \mathrm{E}\right)$, and Kohlschütter $\left(15^{\circ} \mathrm{N}, 154^{\circ} \mathrm{E}\right)$ (Fig. 1). The farside northern hemisphere corresponds to the highest parts of the topography and the thickest parts of the crust of the Moon. This region is also characterized by a central anorthositic region that constitutes the remnant of an anorthositic craton resulting from early lunar differentiation and is known as "Feldspathic Highland Terrane (FHT)" (Jolliff et al., 2000). Although mare deposits cover less than $1 \%$ of this region, these deposits provide insight into the crustal evolution and volcanic history of the FHT. Based on our new crater sizefrequency measurements, we will discuss how long mare volcanism in the central region of the northern farside was active and whether a difference existed in the durations of mare volcanisms in the region and the SPA basin.

The SPA basin is the largest impact feature on the Moon. It is more than $8 \mathrm{~km}$ deep and extends $\sim 2500 \mathrm{~km}$ from the South Pole to the crater Aitken (e.g., Wilhelms, 1987; Spudis et al., 1994; Smith et al., 1997), which is located $15^{\circ}$ south of the equator. According to lunar crustal thickness models (e.g., Neumann et al., 1996; Wieczorek and Phillips, 1998), the mean crustal thickness within the SPA basin is less than a half of that in the central region of the northern farside. We will discuss the effects of the large impact on mare formation from the viewpoint of the duration of mare volcanism by comparing the model ages for mare basalts in the FHT and SPA basin.

\section{Technique of Age Determination}

Crater counting is a well-established technique for deriving the relative and absolute ages of planetary surfaces. Based on the simple idea that older surfaces accumulate more craters, we can infer the relative and absolute ages by measuring the crater size-frequency distribution (CSFD) with image data. This technique has been described in detail in a number of papers (e.g., Arvidson et al., 1979; Neukum and Ivanov, 1994; Hiesinger et al., 2000, 2003; Hartmann and Neukum, 2001; Neukum et al., 2001; Wagner et al., 2002). Therefore we will just briefly present the procedure.

Determining the ages of photogeologic units with crater size-frequency measurements requires two procedures: (1) measuring the surface area of the unit and (2) measuring primary crater diameters within the unit (Hiesinger et al., 2000). In this study, we manually performed crater counts on the computer. We used images that are converted to stereographic projection with a resolution of $10 \mathrm{~m} / \mathrm{pixel}$ at the projection center because the projection introduces little distortion in a narrow area. The diameters of small craters were calculated by multiplying a crater diameter in units of image pixels and the pixel resolution $(10 \mathrm{~m} / \mathrm{pixel})$.

Age estimates from crater size-frequency measurements are sensitive to any contamination by secondary craters. It has been discussed in previous studies of lunar and Martian crater densities that the majority of small craters, not only those in clusters or rays, are secondary in origin, and that some of these secondary craters may not be obvious (e.g., Namiki and Honda, 2003; McEwen et al., 2005; Hirata and Nakamura, 2006; McEwen and Bierhaus, 2006; Dundas and McEwen, 2007). However, this argument has been challenged by various observations. The encounter rates of bolides with Earth's atmosphere determined from satellite records and the small crater production function on the Moon appear to be in good agreement (e.g., Ivanov, 2006). Also, the size-frequency distributions of lunar and Martian craters appear invariant over long time scales (e.g., Neukum and Ivanov, 1994; Werner et al., 2009). Therefore, we believe that craters over a wide diameter range are primary, although the contribution of secondary craters to the population of small craters must continue to be studied. In this 
study, we eliminated obvious secondary craters based on their morphological characteristics (e.g., chain craters, elliptical craters, and clusters) (Melosh, 1989).

We used the cumulative crater size-frequency diagram (e.g., Arvidson et al., 1979) because the cumulative presentation has the advantage of lower variability with statistical noise. We assume that a lunar CSFD can be expressed by the following crater production function polynomial proposed by Neukum and co-workers (Neukum, 1983; Neukum and Ivanov, 1994),

$$
\log _{10} N(D)=a_{0}+\sum_{n=1}^{11} a_{n}\left(\log _{10} D\right)^{n}
$$

where $D$ is the crater diameter in kilometers and $N(D)$ is the cumulative number of craters larger than $D$ per $\mathrm{km}^{2}$. We assigned commonly accepted values for the coefficients of $a_{1}$ to $a_{11}$ (Neukum, 1983; Neukum and Ivanov, 1994). By fitting the observed CSFD to Eq. (1), we derived the crater frequency (cumulative crater density for $D \geq 1 \mathrm{~km}$, i.e., $N(1)$ ). More recently, the polynomial coefficients were updated (Neukum et al., 2001). However, in the diameter range $(<1 \mathrm{~km})$ used in this study, the differences between the polynomials are insignificant (Neukum et al., 2001) and hardly produce differences in the estimated ages.

The cratering chronology formulated by relating crater frequencies to the radiometric ages of Apollo and Luna samples enables us to convert the crater frequencies into absolute model ages (e.g., Hartmann, 1970, 1972; Neukum et al., 1975; Neukum, 1983; Neukum and Ivanov, 1994; Stöffler and Ryder, 2001). In this study, we translated the crater frequency into an absolute model age using the following cratering chronology model proposed by Neukum (1983) and Neukum and Ivanov (1994),

$N(D \geq 1)=5.44 \times 10^{-14}\{\exp (6.93 \times t)-1\}+8.38 \times 10^{-4} t$

where $N(D \geq 1)$ is the cumulative number of craters $\geq 1 \mathrm{~km}$ in diameter per $\mathrm{km}^{2}$ and $t$ is the age in Gyr. More recently, a different chronology model was proposed (Stöffler and Ryder, 2001), indicating a steeper slope in the age range of $>3.75 \mathrm{Ga}$, where the difference from the model we adopt becomes large. However, in the range of $<3.6 \mathrm{Ga}$, the ages from their model differ from our results by less than $0.1 \mathrm{Ga}$.

Model ages from crater counts are principally limited by statistical errors (Neukum et al., 2001). The statistical error of individual data points in our crater frequency measurements is mostly $<20 \%(1 \sigma)$; the errors of ages based on the chronology model are $\pm 0.02 \mathrm{Ga}$ for $>3.5 \mathrm{Ga}, 0.01$ to $0.03 \mathrm{Ga}$ for between 3.2 and $3.0 \mathrm{Ga}$, and $< \pm 20 \%$ for $<3.0 \mathrm{Ga}$ (Hiesinger et al., 2000). It must be noted that these are uncertainties of each data point in CSFD, and the variation from point to point is not represented by these errors.

The synchronous rotation of the Moon generates an apexantapex asymmetry in cratering production rate (Morota and Furumoto, 2003; Morota et al., 2005; Le Feuvre and Wieczorek, 2008; Gallant et al., 2009). However, in the region investigated by our study, the effect of the apexantapex cratering asymmetry on age determination is estimated to be less than 7\% (Gallant et al., 2009), much smaller than the error due to statistical fluctuation. Therefore, we excluded the effect in this study.

Lunar geologic history is subdivided into five chronologic periods defined by impact events that formed the Nectaris basin, the Imbrium basin, the crater Eratosthenes, and the crater Copernicus. Various authors defined lunar chronologic systems in different ways (e.g., Neukum, 1983; Wilhelms, 1987; Neukum and Ivanov, 1994; Stöffler and Ryder, 2001). Estimates of the beginning of the Eratosthenian Period agree well among Neukum (1983), Wilhelms (1987), and Neukum and Ivanov (1994) at 3.2 Gyr, and Stöffler and Ryder (2001) at 3.15 Gyr. However, there are differences in the definitions for the beginnings of the Nectarian, Imbrian, and Copernican given in detail by Hiesinger et al. $(2000,2003)$ and Wagner et al. (2002). The cratering model ages for the major impact basins fall within the range of radiometric ages published by several investigators (see Neukum, 1983; Neukum and Ivanov, 1994; Hiesinger et al., 2000, 2003; Wagner et al., 2002). In this study, therefore, we adopt the chronologic system of Neukum (1983) and Neukum and Ivanov (1994), with Nectaris being $4.1 \pm 0.1 \mathrm{Gyr}$, the Imbrium basin being 3.91 \pm 0.1 Gyr old, and the Copernican Period beginning 1.5 Gyr ago.

\section{Results}

\subsection{Lacus Luxuriae}

Mare deposit, Lacus Luxuriae is located at the center of the $600 \mathrm{~km}$-diameter Freundlich-Sharonov basin $\left(18.5^{\circ} \mathrm{N}\right.$, $175^{\circ} \mathrm{E}$ ) and has a diameter of $50 \mathrm{~km}$ (Fig. 1). The mare deposit was previously mapped as Imbrian age (StuartAlexander, 1978).

Figure 2 presents a TC mosaic image of Lacus Luxuriae and the Buys-Ballot region, obtained with a low solar elevation angle of $\sim 7^{\circ}$. The northern part of Lacus Luxuriae exhibits relatively lower albedo than the southern part. This difference is probably not due to compositional differences in mare basalts, but to vertical and horizontal impact mixing with low-iron and low-titanium highland materials in the southern unit.

We performed crater counts in the northern unit (area $\mathrm{N}$ ) and in the southern unit (area S) (Fig. 2). The results are presented in Fig. 3 as cumulative size-frequency plots (e.g., Arvidson et al., 1979). The model age of the southern unit is estimated to be 3.4-3.5 Ga from the CSFD for $D<400 \mathrm{~m}$ (Table 1); thus, it is classified as an Upper Imbrian Epoch. However, the CSFD for $D>500 \mathrm{~m}$ gives a model age of $\sim 3.7 \mathrm{Ga}$. The deflection of the CSFD, generating two distinct model ages, can be associated with a possible resurfacing event (e.g., Neukum and Horn, 1976; Greeley et al., 1993; Hiesinger et al., 2002; Wagner et al., 2002; Michael and Neukum, 2007). In our interpretation, the southern unit has been resurfaced by a basaltic eruption at 3.4-3.5 Ga, where the erupted lava flow did not completely obliterate pre-existing craters on a deposit formed at $\sim 3.7 \mathrm{Ga}$. The data suggest the diameters of obliterated craters are less than $500 \mathrm{~m}$. Thus, based on the experiential relationship between the diameter and rim height for fresh lunar craters (Pike, 1977), the thickness of the younger flow can be estimated as $15-22 \mathrm{~m}$. 
Table 1. Model ages of mare deposits.

\begin{tabular}{|c|c|c|c|c|c|c|}
\hline Mare deposit & & $\begin{array}{c}\text { Count area } \\
{\left[\mathrm{km}^{2}\right]}\end{array}$ & $\begin{array}{c}N(1)^{\mathrm{a}} \\
{\left[\mathrm{km}^{-2}\right]}\end{array}$ & $\begin{array}{l}\text { Model age } \\
{[\mathrm{Ga}]}\end{array}$ & Stuart-Alexander (1978) & Wilhelms (1987) \\
\hline \multirow[t]{2}{*}{$\begin{array}{l}\text { Lacus Luxuriae } \\
\left(19^{\circ} \mathrm{N}, 176^{\circ} \mathrm{E}\right)\end{array}$} & $\mathrm{N}$ & 213.9 & $\begin{array}{l}0.00316 \\
0.00958\end{array}$ & $\begin{array}{l}3.28(+0.06 /-0.08) \\
3.68(+0.07 /-0.12)\end{array}$ & $\operatorname{Im}^{\mathrm{b}}$ & \\
\hline & $\mathrm{S}$ & 75.7 & $\begin{array}{l}0.00430 \\
0.00898\end{array}$ & $\begin{array}{l}3.46(+0.03 /-0.04) \\
3.67(+0.06 /-0.10)\end{array}$ & $\operatorname{Im}^{\mathrm{b}}$ & \\
\hline $\begin{array}{l}\text { Buys-Ballot } \\
\left(21^{\circ} \mathrm{N}, 175^{\circ} \mathrm{E}\right)\end{array}$ & & 86.3 & 0.00295 & $3.22(+0.10 /-0.18)$ & $\operatorname{Im}^{\mathrm{b}}$ & \\
\hline $\begin{array}{c}\text { Campbell } \\
\left(45^{\circ} \mathrm{N}, 151^{\circ} \mathrm{E}\right)\end{array}$ & & 481.0 & 0.00229 & $2.72(+0.24 /-0.29)$ & $\operatorname{Im}^{\mathrm{b}}$ & $\mathrm{Im}^{\mathrm{b}}$ \\
\hline $\begin{array}{l}\text { Kohlschütter } \\
\left(15^{\circ} \mathrm{N}, 154^{\circ} \mathrm{E}\right)\end{array}$ & & 183.0 & 0.00261 & $3.03(+0.24 /-0.56)$ & $\operatorname{Im}^{\mathrm{b}}$ & \\
\hline
\end{tabular}

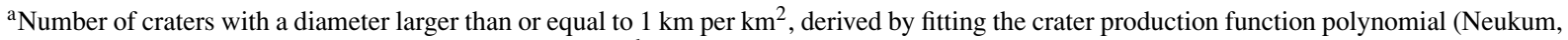
1983; Neukum and Ivanov, 1994) to the observed CSFD. ${ }^{\mathrm{b}} \mathrm{Im}=$ Imbrian mare material.

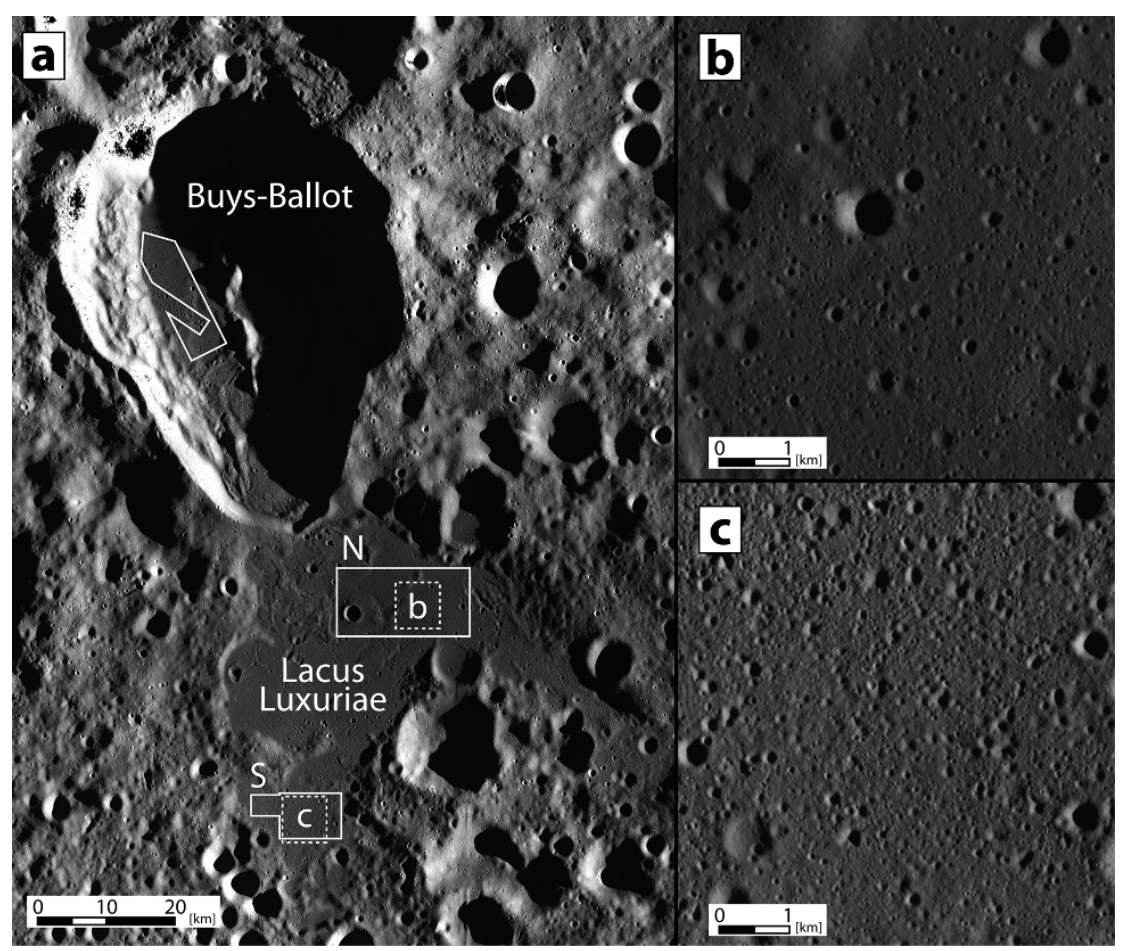

Fig. 2. (a) TC mosaic image of Lacus Luxuriae and Buys-Ballot. Mean solar elevation angle of the original images is $\sim 7$ degree. Counting areas are indicated by white lines. The bizarre shape of the count area for Buys-Ballot is due to excluding an area occupied by numerous secondary craters. (b and c) Close-up images of the northern unit and the southern unit in Lacus Luxuriae, respectively. The locations of these areas are shown as dashed boxes in (a). Stereographic projection centered at $20^{\circ} \mathrm{N}$ latitude and $175^{\circ} \mathrm{E}$ longitude.

The CSFD for the northern unit also exhibits evidence of resurfacing events. For the lava flow exposed in the northern unit, the CSFD for $D<450 \mathrm{~m}$ gives a model age of $\sim 3.3 \mathrm{Ga}$, younger than that of the southern unit (Table 1). The result supports the interpretation that the higher albedo of the southern part is mainly due to impact mixing with highland materials. From the CSFD for $D>$ $650 \mathrm{~m}$, the model age of the underlaid flow is estimated to be $\sim 3.7 \mathrm{Ga}$, which is equivalent to that of the flow under the southern unit. Therefore, we consider the lava flow under the northern unit to be the same as that under the southern unit. Furthermore, we note that the CSFD for $0.45 \mathrm{~km}<$ $D<0.6 \mathrm{~km}$ lies on the polynomial of $3.46 \mathrm{Ga}$, although the errors are significantly large. This result implies that the lava flow of 3.4-3.5 Ga exposed in the southern unit would spread under the northern unit. From the crater diameterrim height relation (Pike, 1977), the thickness of the lava flow of $\sim 3.3 \mathrm{Ga}$ is estimated to be $13-19 \mathrm{~m}$, and that of $3.4-3.5 \mathrm{Ga}$ is estimated to be $19-28 \mathrm{~m}$.

Our results indicate that mare volcanism in Lacus Luxuriae began at least $23.7 \mathrm{Gyr}$ ago and continued through the Late Imbrian Epoch, that is consistent with the previous mapping as Imbrian age (Stuart-Alexander, 1978).

\subsection{Buys-Ballot}

Buys-Ballot, which lies just northwest of Lacus Luxuriae, is a $55 \mathrm{~km}$-diameter Imbrian crater (StuartAlexander, 1978) or Nectarian crater (Wilhelms, 1987). The odd shape exhibits the distinctive signatures of a very low-angle impact: elongated pear-shaped plan $(90 \times$ $60 \mathrm{~km}$ ), crater widening transverse to the inferred trajectory, 


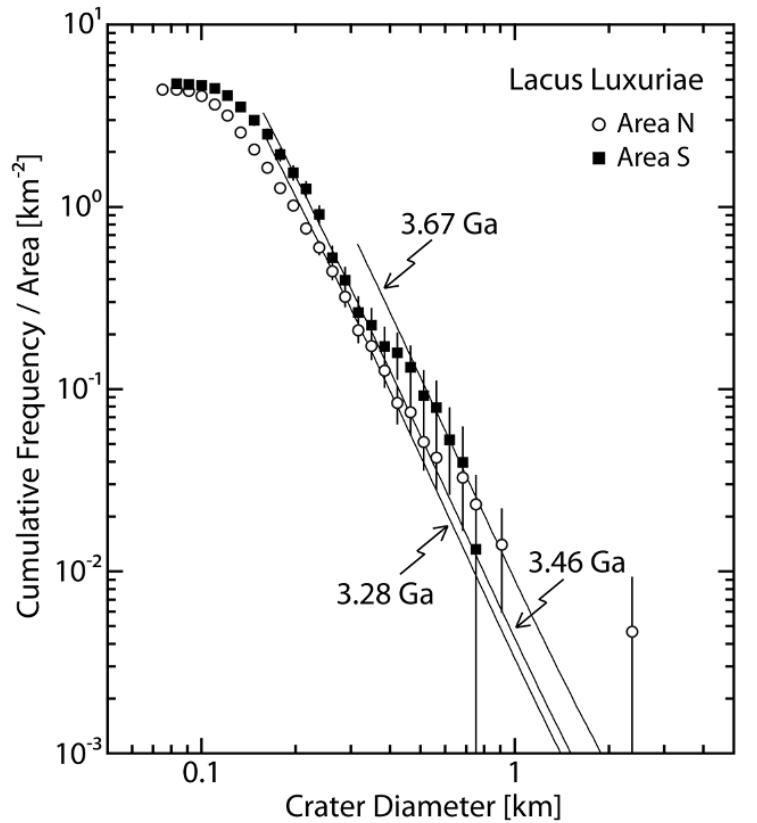

Fig. 3. Cumulative crater size-frequency distributions of Lacus Luxuria. Solid curves indicate the crater production function polynomial fitted to the observed CSFDs (Neukum, 1983; Neukum and Ivanov, 1994). Error bars are calculated by $\log \left(N \pm N^{1 / 2}\right) / A$, where $N$ is the cumulative number of craters and $A$ is the counted area.

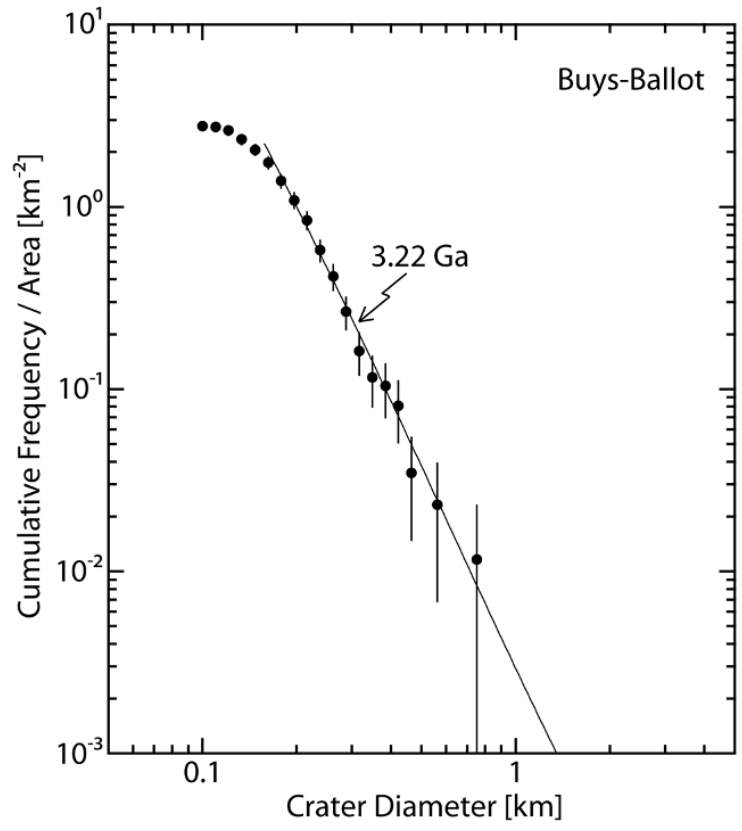

Fig. 4. Cumulative crater size-frequency distribution of the mare deposit in Buys-Ballot. Solid curve indicates the crater production function polynomial fitted to the observed CSFDs (Neukum, 1983; Neukum and Ivanov, 1994). Error bars are calculated by $\log \left(N \pm N^{1 / 2}\right) / A$, where $N$ is the cumulative number of craters and $A$ is the counted area.

and central peak ridge (Schultz et al., 1998) (Fig. 2). The floor of this crater is filled by mare basalt with iron content estimated to be $8-15 \mathrm{wt} \%$ and titanium content estimated to be 0-2 wt\% from Clementine spectral data (Gillis and Spudis, 1998).

We performed crater size-frequency measurement in the eastern part of the floor (Fig. 2). Figure 4 plots the result as cumulative size-frequency distribution. The mare deposit exhibits no evidence of any resurfacing events in the CSFD; the observed CSFD can be well-fitted by one polynomial function for the investigated diameter range $(>250 \mathrm{~m})$. The model age is estimated to be $3.2-3.3 \mathrm{Ga}$, which is equivalent to that of the exposed lava flow in the northern unit of Lacus Luxuriae $(\sim 3.3 \mathrm{Ga})$ within the uncertainties, suggesting that the lava flows might have formed from the same magma (Table 1).

\subsection{Campbell}

Campbell is a $220 \mathrm{~km}$-diameter pre-Nectarian crater (Stuart-Alexander, 1978; Wilhelms, 1987). Mare basalt covers an area of $2400 \mathrm{~km}^{2}$ within the central western portion of the crater and was previously mapped as Imbrian age (Stuart-Alexander, 1978; Wilhelms, 1987). The basalt has low iron (10-14 wt\% FeO) and low titanium (0.5-1.5 wt\% $\mathrm{TiO}_{2}$ ) contents. Furthermore, the concentration of mafic material is constant and does not vary across the expanse of the mare (Gillis and Spudis, 1996, 1998).

Figure 5 presents a TC mosaic image of the mare deposit within Campbell, obtained with a low solar elevation angle of $\sim 5^{\circ}$. We carried out crater counts in the central area of this mare. To the northeast of the area there is a fresh rayed crater with a diameter of $3.2 \mathrm{~km}$, which may be accompanied by numbers of secondary craters. However, most expected secondaries are estimated to be smaller than $160 \mathrm{~m}$ in diameter, i.e. below the minimum size of our study $(250 \mathrm{~m})$, according to the relationship between primary crater diameter and mean maximum secondary crater diameter for lunar craters (Allen, 1979). In any case, we eliminated obvious secondary craters based on their morphological characteristics, such as chain craters, elliptical craters, and clusters.

Figure 6 plots the cumulative size-frequency distribu-

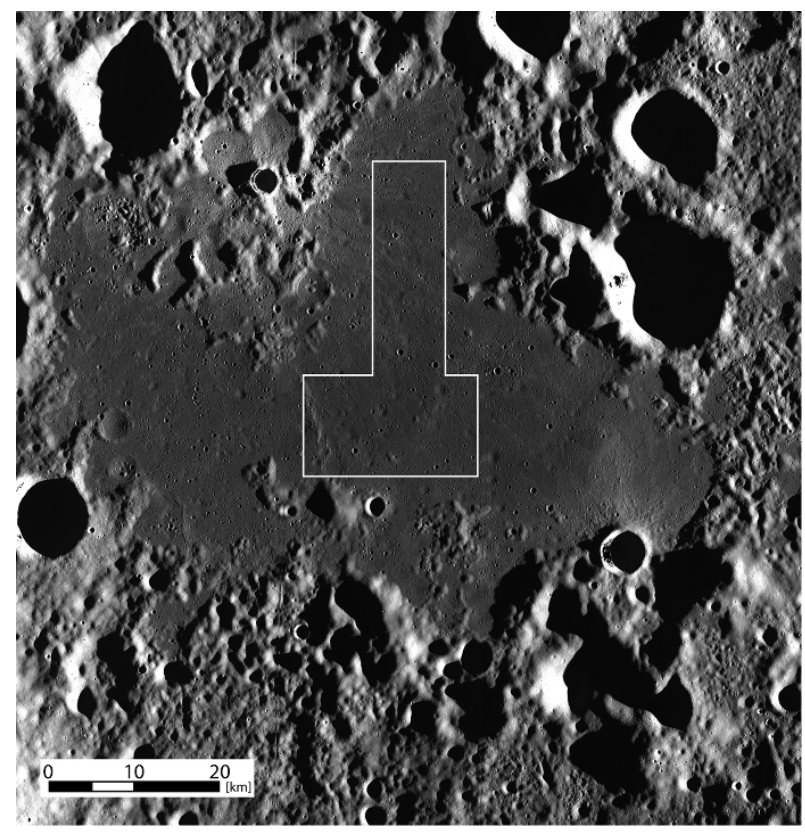

Fig. 5. TC mosaic image of the mare deposit in Campbell. Mean solar elevation angle of the original images is $\sim 5$ degree. Counting area is indicated by white lines. Stereographic projection centered at $45.5^{\circ} \mathrm{N}$ latitude and $151^{\circ} \mathrm{E}$ longitude. 


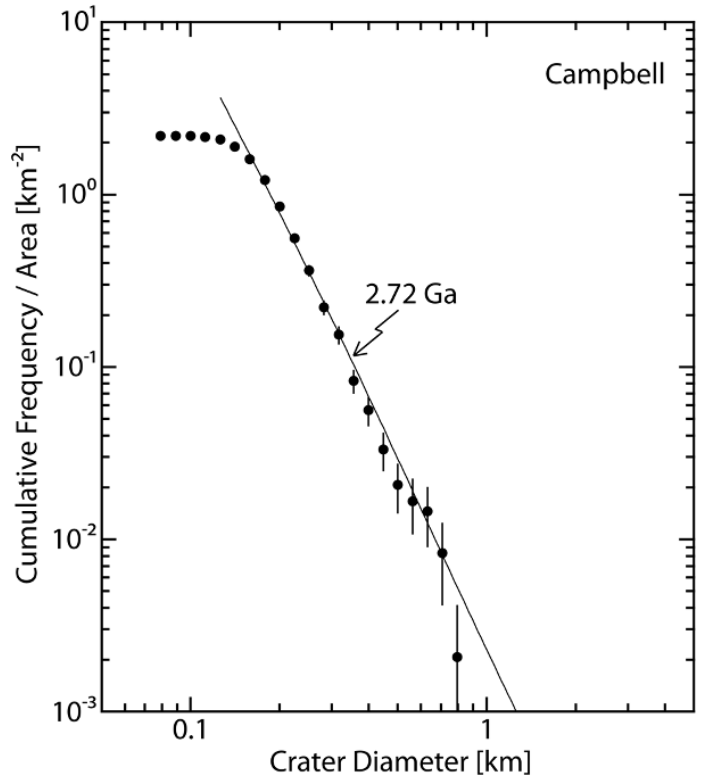

Fig. 6. Cumulative crater size-frequency distribution of the mare deposit in Campbell. Solid curve indicates the crater production function polynomial fitted to the observed CSFDs (Neukum, 1983; Neukum and Ivanov, 1994). Error bars are calculated by $\log \left(N \pm N^{1 / 2}\right) / A$, where $N$ is the cumulative number of craters and $A$ is the counted area.

tion of counted craters. The observed CSFD can be fitted to one production function polynomial for the investigated diameter range $(>250 \mathrm{~m})$. The derived model age of this deposit is estimated to be $\sim 2.7 \mathrm{Ga}$; hence, it is substantially younger than the Imbrian-Eratosthenian boundary (3.2 Ga). Haruyama et al. (2009) also found that several farside maria (e.g., Apollo, Antoniadi, and the eastern part of Mare Moscoviense) formed in the Eratosthenian Period. Our result indicates that the mare basalt in Campbell is one of the mare deposits formed in the latest phase of farside volcanism.

\subsection{Kohlschütter}

Kohlschütter, which is located to the southeast of the Mare Moscoviense (Fig. 1), is a $53 \mathrm{~km}$-diameter Nectarian crater (Stuart-Alexander, 1978; Wilhelms, 1987). The floor of the crater is partially covered by mare basalt. The mare deposit was previously classified as Imbrian in age (StuartAlexander, 1978).

Figure 7 presents a TC mosaic image of the mare deposit within Kohlschütter, obtained with a low solar elevation angle of $\sim 6^{\circ}$. In the central western part of the floor, which corresponds to the highly cratered area, highland material remains uncovered by mare basalt. The northern part of the floor is also occupied by clusters of secondary craters from the 20-km-diameter rayed crater that lies northwest of Kohlschütter (Fig. 1). Therefore, we chose the southeastern part of the floor as the count area (Fig. 7). We also excluded a mare ridge, possibly formed by a vertical displacement of mare lava (e.g., Lucchitta, 1976), from the count area because it makes shades particularly in the northeastern part of the count area, inhibiting identification of small craters in particular.

Figure 8 plots the result as a cumulative size-frequency distribution. The observed CSFD can be fitted to one pro-

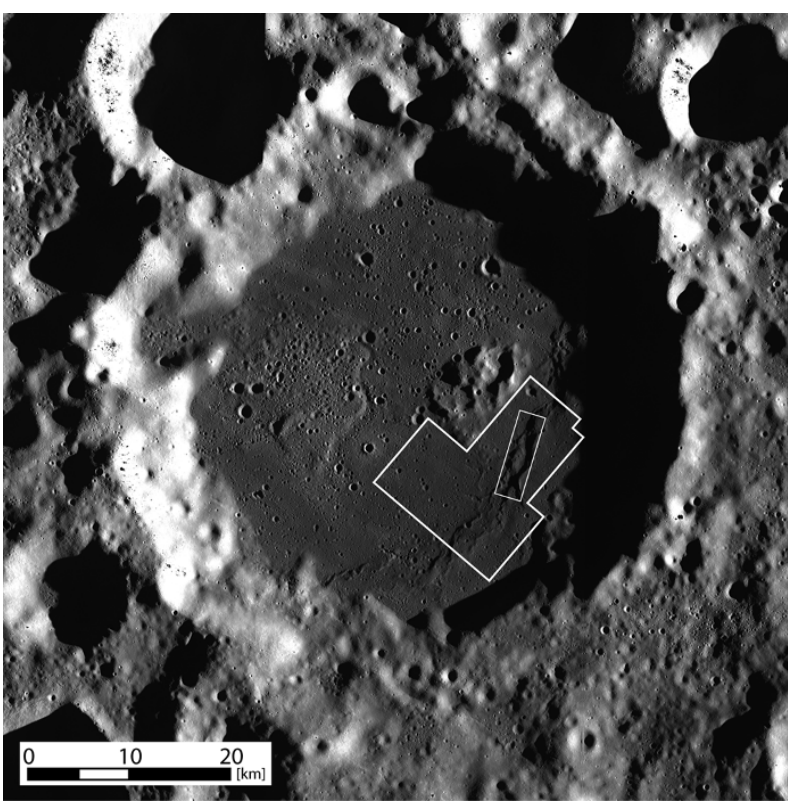

Fig. 7. TC mosaic image of the crater Kohlschütter. Mean solar elevation angle of the original images is $\sim 6$ degree. Counting area is indicated by white lines. The mare ridge area indicated by a white box was excluded from the count area because it inhibits identification of small craters (see the text). Stereographic projection centered at $14^{\circ} \mathrm{N}$ latitude and $154^{\circ} \mathrm{E}$ longitude.

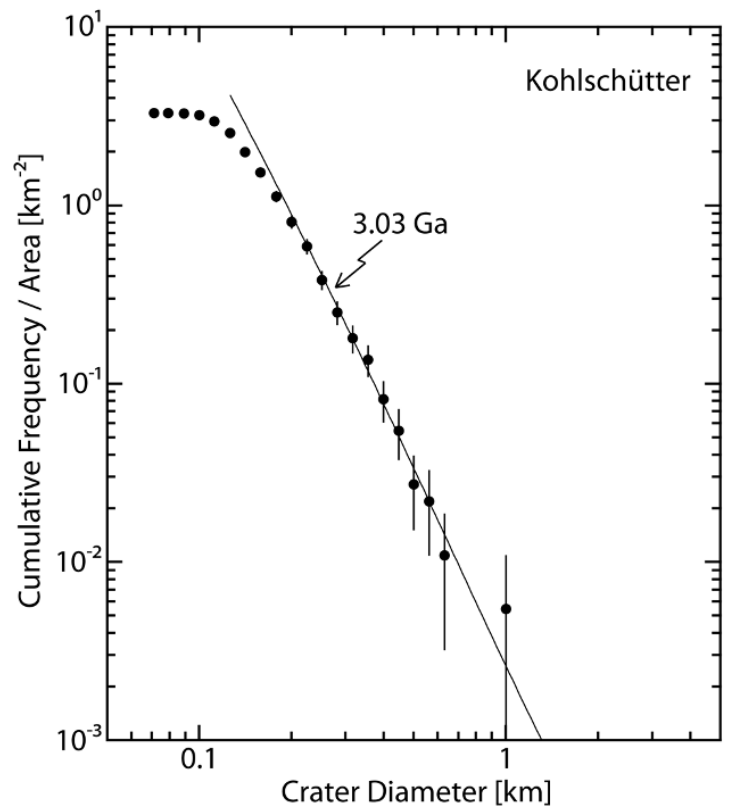

Fig. 8. Cumulative crater size-frequency distributions of the mare deposit in Kohlschütter. Solid curve indicates the crater production function polynomial fitted to the observed CSFDs (Neukum, 1983; Neukum and Ivanov, 1994). Error bars are calculated by $\log \left(N \pm N^{1 / 2}\right) / A$, where $N$ is the cumulative number of craters and $A$ is the counted area.

duction function polynomial for the investigated diameter range $(>250 \mathrm{~m})$. The model age is estimated to be $\sim 3.0 \mathrm{Ga}$, younger than the Imbrian-Eratosthenian boundary. However, it must be noted that the error of the model age estimated in our study is close to $\pm 20 \%(1 \sigma)$. If we adopt the upper limit of the error range, the mare basalt should be classified as Upper Imbrian. 


\section{Discussion}

\subsection{Duration of mare volcanism in the FHT}

The model ages of mare basalts investigated in our study range from 3.7 to $2.7 \mathrm{Gyr}$ ago (i.e., from the Late Imbrian Epoch to the Eratosthenian Period). The oldest basalt was found in Lacus Luxuriae as a layer buried by later flows. In contrast, the youngest basalt occurs in Campbell. No evident correlations exist between the model ages and the topography, the gravity anomaly, and the sizes and ages of the craters or the basins filled by the mare basalts.

Mare Moscoviense, which is one of the most outstanding mare deposits on the lunar farside, is also located in the FHT on which our study focused (Fig. 1). Previous dating of four mare units in Mare Moscoviense using TC image data (Haruyama et al., 2009; Morota et al., 2009) revealed that

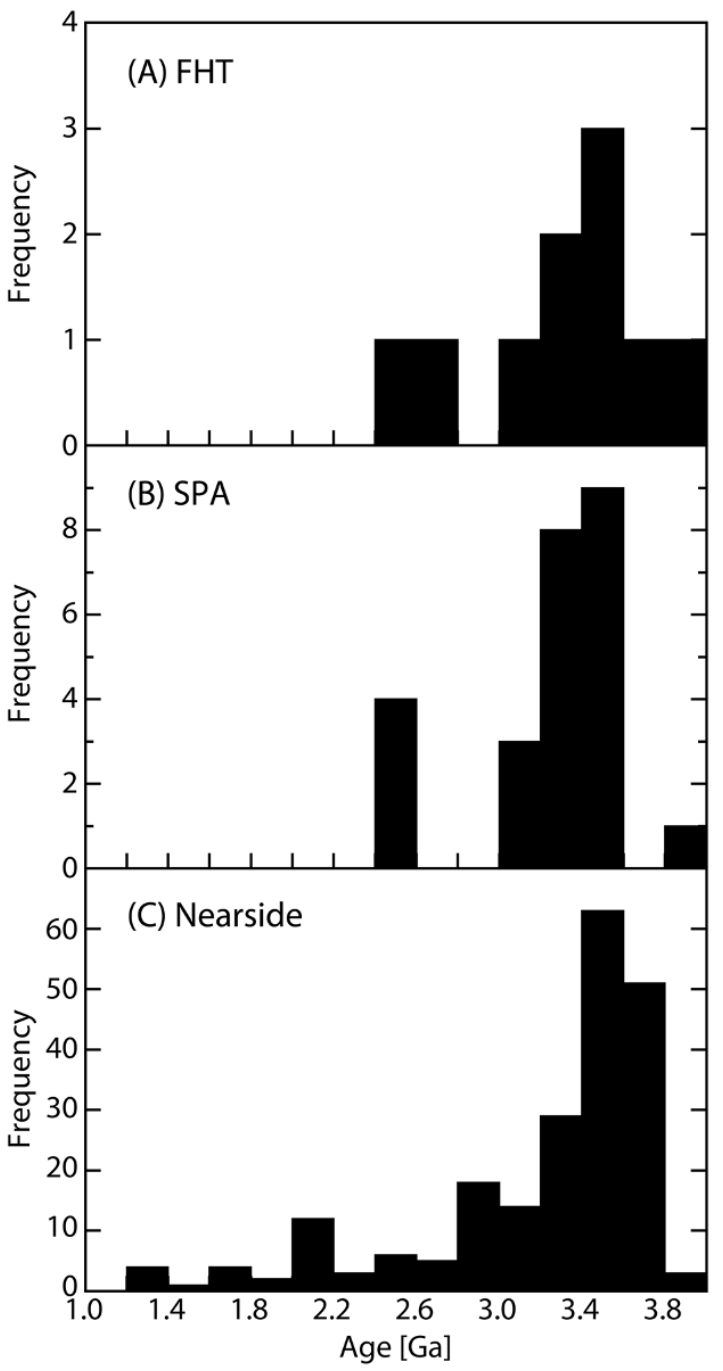

Fig. 9. Histograms of the model ages of mare deposits in the central region of the northern farside (A), including Lacus Luxuriae, Buys-Ballot, Campbell, Kohlschütter (this study), and those in Mare Moscoviense (Haruyama et al., 2009; Morota et al., 2009), within the SPA basin (B), including Poincaré, Ingenii, Antoniadi, Chrétien, Jules Verne, Aitken, Apollo, Von Karman, Von Karman M, Leibnitz, Rumford, Maksutov, and Nishina (Haruyama et al., 2009), and on the nearside (C), including those in Mare Imbrium, Serenitatis, Humorum, Tranquillitatis, Humboldtinum (Hiesinger et al., 2000), Oceanus Procellarum, Mare Nubium, Cognitum, Insularum (Hiesinger et al., 2003), and Mare Fecunditatis (Hiesinger et al., 2006). the lava flows were formed from 3.9 to 2.6 Gyr ago. Figure 9(A) presents the frequency distribution of model ages for all investigated mare deposits in the FHT, indicating that most lava flows in the FHT formed in the Late Imbrian Epoch. However, three deposits (Campbell, Kohlschütter, and the eastern unit in Mare Moscoviense) indicate younger model ages. Thus, we conclude that mare volcanism in the FHT continued until 2.6 Gyr ago.

Previous studies of dark haloed craters and light plains revealed the presence of cryptomaria (i.e., maria that were buried by ejecta from large craters or basins) and interpreted them as evidence for ancient mare volcanism (e.g., Schultz and Spudis, 1978, 1983; Hawke and Bell, 1981; Bell and Hawke, 1984; Antonenko et al., 1995). Such ancient mare volcanism has been supported by radiometric analyses of rock samples returned from the lunar nearside (e.g., Taylor et al., 1983; Dasch et al., 1987; Nyquist et al., 2001) and lunar meteorites (Terada et al., 2007), which indicate ages of 4.2-4.35 Gyr for their basalt clasts. In the central northern region of the farside, the onset of mare volcanism is not well understood, even though our results indicate that mare volcanism began at least as early as $3.9 \mathrm{Gyr}$ ago, for a total duration of $\sim 1.3$ Gyr. However, the total duration in the region might be expanded to $\sim 1.7 \mathrm{Gyr}$, if the light plains that can be found as small patches in the FHT (Howard et al., 1974) are associated with cryptomaria.

\subsection{Comparison with the SPA basin and the nearside}

Figures 9(B) and 9(C) present histograms of model ages for mare deposits in the SPA basin (Haruyama et al., 2009) and on the nearside (Hiesinger et al., 2000, 2003, 2006) for comparison. We found that the shape of the frequency distribution of mare basalts in the FHT is very similar to that in the SPA basin; the histograms have a peak at $\sim 3.5 \mathrm{Gyr}$, and expand to $\sim 2.5$ Gyr. However, it must be noted that some cryptomaria exist within the SPA basin (e.g., Pieters et al., 2001), implying that mare volcanism in the SPA basin may have started prior to that in the FHT, though the volumes of the cryptomare deposits are not so large.

The effects of large impacts on the thermal evolution of the mantle have been proposed as one mechanism for the formation of lunar basalts (e.g., Arkani-Hamed, 1973, 1974; Elkins-Tanton et al., 2004; Ghods and ArkaniHamed, 2007). A recent version of the mechanism, related to the mantle convection triggered by impact-induced thermal perturbations (Ghods and Arkani-Hamed, 2004, 2007), requires that the SPA basin formation impact generates a substantial amount of melting in the mantle, which does not seem to be compatible with the minor amount of mare and cryptomare deposits filling this basin. Furthermore, the impact-induced convection model requires a long duration of mare volcanism for the SPA basin (Ghods and ArkaniHamed, 2007). This is also incompatible with our result, which indicates no difference in the timing and the duration of mare volcanism within and outside the SPA basin. Thus, we concluded that the SPA basin formation impact had a minor effect on the formation of mare basalts in the region. It is probable that the basin simply provided a depression for magma generated by internal heating in early history to pond.

As presented by Haruyama et al. (2009), comparing 
model ages of mare basalts on the farside and those on the nearside indicates that the timing of the termination of mare volcanism differed between the farside $(\sim 2.5 \mathrm{Ga})$ and the nearside $(\sim 1.2 \mathrm{Ga})$. This difference might be related to the thicker crust (e.g., Head and Wilson, 1992) and/or a deficiency of heat-producing radioactive elements on the farside (e.g., Jolliff et al., 2000). However, a more solid interpretation of the causes for the nearside-farside dichotomy in mare volcanism requires a clearer understanding of the ages, volumes, compositions of mare basalts, and relation to crustal structure. Such clarification will be possible with SELENE multispectral (Matsunaga et al., 2008; Ohtake et al., 2009), topography (Araki et al., 2009), and gravity (Namiki et al., 2009) data sets.

\section{Summary}

The new high-resolution images obtained by SELENE TC enable us to perform accurate crater size-frequency measurements in the mare deposits in the central region of the northern farside, which were previously undated. Our results indicated that the mare deposits in the region formed from 3.7 to $2.7 \mathrm{Gyr}$ ago. From model ages for all mare deposits in the region investigated by both our study and previous studies (Haruyama et al., 2009; Morota et al., 2009), we found that mare volcanism in this region began at least as early as 3.9 Gyr ago, and continued until $\sim 2.6$ Gyr ago. The comparison of model ages in the region and the SPA basin indicates the simultaneity of the mare volcanism in these regions. Therefore, we concluded that the SPA basin formation impact simply provided a depression for magma generated by internal heating in early history to pond rather than affecting the formation of mare basalts in the region.

Acknowledgments. We thank all the contributors to the SELENE (Kaguya) project and Lunar Imager/Spectrometer (LISM) working group for their efforts in development, operation, and data processing of SELENE and LISM. We are grateful to C. R. Chapman and R. Wagner for thoughtful and constructive comments in their review of this paper. We also thank J. Oberst for his helpful comments. This work was supported by the Japan Society for the Promotion of Science under a Grant-in-Aid for JSPS Fellows (20.9211: T. Morota), a Grant-in-Aid for Scientific Research (C) (20540416: J. Haruyama), and a Grant-in-Aid for Scientific Research (A) (19204045: H. Demura).

\section{References}

Allen, C. C., Large lunar secondary craters-Size-range relationships, Geophys. Res. Lett., 6, 51-54, doi:10.1029/GL006i001p00051, 1979.

Antonenko, I., J. W. Head, J. F. Mustard, and B. R. Hawke, Criteria for the detection of lunar cryptomaria, Earth Moon Planets, 69, 141-172, doi:10.1007/BF00613096, 1995

Araki, H., S. Tazawa, H. Noda, Y. Ishihara, S. Goossens, S. Sasaki, N. Kawano, I. Kamiya, H. Otake, J. Oberst, and C. Shum, Lunar global shape and polar topography derived from Kaguya-LALT laser altimetry, Science, 323, 897-900, doi:10.1126/science.1164146, 2009.

Arkani-Hamed, J., On the formation of the lunar mascons, Proc. Lunar Sci. Conf. 4th, 2673-2684, 1973.

Arkani-Hamed, J., Effect of a giant impact on the thermal evolution of the Moon, Moon, 9, 183-209, doi:10.1007/BF00565403, 1974.

Arvidson, R., J. Boyce, C. Chapman, M. Cintala, H. Moore, G. Neukum, P. Schultz, L. Soderblom, R. Strom, A. Woronow, and R. Young, Standard techniques for presentation and analysis of crater size-frequency data, Icarus, 37, 467-474, doi:10.1016/0019-1035(79)90009-5, 1979.

Bell, J. F. and B. R. Hawke, Lunar dark-haloed impact craters: origins and implications for early mare volcanism, J. Geophys. Res., 8, 6899-1147, 10.1029/JB089iB08p06899, 1984.
Boyce, J. M., Ages of flow units in the lunar nearside maria based on Lunar Orbiter IV photographs, Proc. Lunar Sci. Conf. 7th, 2717-2728, 1976.

Bugiolacchi, R. and J. E. Guest, Compositional and temporal investigation of exposed lunar basalts in the Mare Imbrium region, Icarus, 197, 1-18, doi:10.1016/j.icarus.2008.04.001, 2008.

Dasch, E. J., C.-Y. Shih, B. M. Bansal, H. Wiesmann, and L. E. Nyquist, Isotopic analysis of basaltic fragments from lunar breccia 14321chronology and petrogenesis of pre-Imbrium mare volcanism, Geochim. Cosmochim. Acta., 51, 3241-3254, doi:10.1016/0016-7037(87)901323, 1987.

Dundas, C. M. and A. S. McEwen, Rays and secondary craters of Tycho, Icarus, 186, 31-40, doi:10.1016/j.icarus.2006.08.011, 2007.

Elkins-Tanton, L. T., B. H. Hager, and T. L. Grove, Magmatic effects of the lunar late heavy bombardment, Earth Planet. Sci. Lett., 222, 17-27, doi:10.1016/j.epsl.2004.02.017, 2004.

Gallant, J., B. Gladman, and M. Cuk, Current bombardment of the EarthMoon system: emphasis on cratering asymmetries, Icarus, 202, 371382, doi:10.1016/j.icarus.2009.03.025, 2009

Ghods, A. and J. Arkani-Hamed, The formation of the lunar and Martian mascons, AGU, Fall Meeting, abstract P23A-0230, 2004.

Ghods, A. and J. Arkani-Hamed, Impact-induced convection as the main mechanism for formation of lunar mare basalts, J. Geophys. Res., 112, E03005, doi:10.1029/2006JE002709, 2007.

Gillis, J. J. and P. D. Spudis, The composition and geologic setting of lunar far side maria, Lunar Planet. Sci. XXVII, 413-414, 1996.

Gillis, J. J. and P. D. Spudis, Inventory of $\mathrm{FeO}$ and $\mathrm{TiO}_{2}$ compositions for mare deposits on the far side of the Moon, Lunar Planet. Sci. XXIX, Abstract \#1521, 1998.

Greeley, R., S. D. Kadel, D. A. Williams, L. R. Gaddis, J. W. Head, A S. McEwen, S. L. Murchie, E. Nagel, G. Neukum, C. M. Pieters, J. M. Sunshine, R. Wagner, and M. J. S. Belton, Galileo imaging observations of lunar maria and related deposits, J. Geophys. Res., 98, 17183-17205, E03005, 1993.

Hartmann, W. K., Lunar cratering chronology, Icarus, 13, 299-301, doi:10.1016/0019-1035(70)90059-X, 1970.

Hartmann, W. K., Paleocratering of the Moon: Review of post-Apollo data, Astrophys. Space Sci., 17, 48-64, doi:10.1007/BF00642541, 1972.

Hartmann, W. K. and G. Neukum, Cratering chronology and the evolution of Mars, Space Sci. Rev., 96, 165-194, doi:10.1023/A:1011945222010, 2001

Haruyama, J., T. Matsunaga, M. Ohtake, T. Morota, C. Honda, Y. Yokota, M. Torii, Y. Ogawa, and the LISM Working Group, Global lunar-surface mapping experiment using the Lunar Imager/Spectrometer on SELENE, Earth Planets Space, 60, 243-255, 2008.

Haruyama, J., M. Ohtake, T. Matsunaga, T. Morota, C. Honda, Y. Yokota, M. Abe, Y. Ogawa, H. Miyamoto, A. Iwasaki, C. M. Pieters, N. Asada, H. Demura, N. Hirata, J. Terazono, S. Sasaki, K. Saiki, A. Yamaji, M. Torii, and J.-L. Josset, Long-lived volcanism on the lunar farside revealed by SELENE Terrain Camera, Science, 323, 905-908, doi:10.1126/science.1163382, 2009.

Hawke, B. R. and J. F. Bell, Remote sensing studies of lunar dark-halo impact craters: preliminary results and implications for early volcanism, Proc. Lunar Sci. Conf. 12th, 665-678, 1981.

Head, J. W. III, Lunar mare deposits: areas, volumes, sequence, and implication for melting in source areas, in Origin of Mare Basalts and their implications for Lunar Evolution, pp. 66-69, Lunar Sci. Inst., Houston, Texas, 1975.

Head, J. W. III and L. Wilson, Lunar mare volcanism: stratigraphy, eruption, conditions, and the evolution of secondary crusts, Geochim. Cosmochim. Acta., 56, 2155-2174, doi:10.1016/0016-7037(92)90183J, 1992.

Hiesinger, H., R. Jaumann, G. Neukum, and J. W. Head III, Age of mare basalts on the lunar nearside, J. Geophys. Res., 105, 29239-29275, doi:10.1029/2000JE001244, 2000 .

Hiesinger, H., J. W. Head III, U. Wolf, R. Jaumann, and G. Neukum, Lunar mare basalt flow units: thickness determined from crater size-frequency distributions, Geophys. Res. Lett., 29, 1248, doi: 10.1029/2002GL014847, 2002.

Hiesinger, H., J. W. Head III, U. Wolf, R. Jaumann, and G. Neukum, Ages and stratigraphy of mare basalts in Oceanus Procellarum, Mare Nubium, Mare Cognitum, and Mare Insularum, J. Geophys. Res., 108, 5065, doi:10.1029/2002JE001985, 2003.

Hiesinger, H., J. W. Head III, U. Wolf, R. Jaumann, and G. Neukum, New ages for basalts in Mare Fecunditatis based on crater size-frequency measurements, Lunar Planet. Sci. XXXVII, Abstract \#1151, 2006.

Hiesinger, H., J. W. Head, U. Wolf, G. Neukum, and R. Jaumann, Ages of mare basalts on the lunar nearside: a synthesis, Lunar Planet. Sci. 
XXXIX, Abstract \#1269, 2008.

Hirata, N. and A. M. Nakamura, Secondary craters of Tycho: sizefrequency distributions and estimated fragment size-velocity relationship, J. Geophys. Res., 111, doi:10.1029/2005JE002484, E03005, 2006.

Howard, K. A., D. E. Wilhelms, and D. H. Scott, Lunar basin formation and highland Stratigraphy, Rev. Geophys. Space Phys., 12, 309-327, 1974.

Ivanov, B. A., Earth/Moon impact rate comparison: Searching constraints for lunar secondary/primary cratering proportion, Icarus, 183, 504-507, doi:10.1016/j.icarus.2006.04.004, 2006

Jolliff, B. L., J. J. Gillis, L. A. Haskin, R. L. Korotev, and M. A. Wieczorek, Major lunar crustal terranes: surface expressions and crust-mantle origins, J. Geophys. Res., 105, 4197-4216, doi:10.1029/1999JE001103, 2000.

Kato, M., S. Sasaki, K. Tanaka, Y. Iijima, and Y. Takizawa, The Japanese lunar mission SELENE: Science goals and present status, Adv. Space Res., 42, 294-300, doi:10.1016/j.asr.2007.03.049, 2008.

Le Feuvre, M. and M. A. Wieczorek, Nonuniform cratering of the terrestrial planets, Icarus, 197, 291-306, doi:10.1016/j.icarus.2008.04.011, 2008 .

Lucchitta, B. K., Mare ridges and related highland scarps-Result of vertical tectonism?, Proc. Lunar Sci. Conf. 7th, 2761-2782, 1976.

Matsunaga, T., M. Ohtake, J. Haruyama, Y. Ogawa, R. Nakamura, Y. Yokota, T. Morota, C. Honda, M. Torii, M. Abe, T. Nimura, T. Hiroi, T. Arai, K. Saiki, H. Takeda, N. Hirata, S. Kodama, T. Sugihara, H. Demura, N. Asada, J. Terazono, and H. Otake, Discoveries on the lithology of lunar crater central peaks by SELENE Spectral Profiler, Geophys. Res. Lett., 35, L23201, doi:10.1029/2008GL035868, 2008.

McEwen, A. S. and E. B. Bierhaus, The importance of secondary cratering to age constraints on planetary surface, Ann. Rev. Earth Planet. Sci., 34, 535-567, doi:10.1146/annurev.earth.34.031405.125018, 2006.

McEwen, A. S., B. S. Preblich, E. P. Turtle, N. A. Artemieva, M. P. Golombek, M. Hurst, R. L. Kirk, D. M. Burr, and P. R. Christensen, The rayed crater Zunil and interpretations of small impact craters on Mars, Icarus, 176, 351-381, doi:10.1016/j.icarus.2005.02.009, 2005.

Melosh, H. J., Impact Cratering: A Geologic Process, Oxford Univ. Press, New York, 1989.

Michael, G. and G. Neukum, Refinement of cratering model age for the case of partial resurfacing, Lunar Planet. Sci. XXXVIII, Abstract \#1825, 2007.

Morota, T. and M. Furumoto, Asymmetrical distribution of rayed craters on the Moon, Earth Planet. Sci. Lett., 206, 315-323, doi:10.1016/ S0012-821X(02)01111-1, 2003.

Morota, T., T. Ukai, and M. Furumoto, Influence of the asymmetrical cratering rate on the lunar cratering chronology, Icarus, 173, 322-324, 10.1016/j.icarus.2004.08.016, 2005.

Morota, T., J. Haruyama, C. Honda, M. Ohtake, Y. Yokota, J. Kimura, T. Matsunaga, Y. Ogawa, N. Hirata, H. Demura, A. Iwasaki, H. Miyamoto, R. Nakamura, H. Takeda, Y. Ishihara, and S. Sasaki, Mare volcanism in the lunar farside Moscoviense region: implication for lateral variation in magma production of the Moon, Geophys. Res. Lett., 36, L21202, doi:10.1029/2009GL040472, 2009.

Namiki, N. and C. Honda, Testing hypotheses for the origin of steep slope of lunar size-frequency distribution for small craters, Earth Planets Space, 55, 39-51, 2003.

Namiki, N., T. Iwata, K. Matsumoto, H. Hanada, H. Noda, S. Goossens, M. Ogawa, N. Kawano, K. Asari, S. Tsuruta, Y. Ishihara, Q. Liu, F. Kikuchi, T. Ishikawa, S. Sasaki, C. Aoshima, K. Kurosawa, S. Sugita, and T. Takano, Farside gravity field of the Moon from four-way Doppler measurements of SELENE (Kaguya), Science, 323, 900-905, doi:10.1126/science.1168029, 2009.

Neukum, G., Meteoritenbombardement und Datierung planetarer Oberflächen, Habilitation Dissertation for Faculty Membership, Ludwig-Maximilians-Univ., Munich, 1983.

Neukum, G. and P. Horn, Effects of lava flows on lunar crater population, The Moon, 15, 205-222, doi:10.1007/BF00562238, 1976.

Neukum, G. and B. A. Ivanov, Cratering size distributions and impact probabilities on Earth from lunar, terrestrial-planet, and asteroid cratering data, in Hazards Due to Comet and Asteroids, edited by T. Gehrels, pp. 359-416, Univ. of Arizona Press, Tucson, 1994.

Neukum, G., B. König, H. Fechtg, and D. Storzer, Cratering in the earthmoon system: Consequences for age determination by crater counting, Proc. Lunar Sci. Conf. 6th, 2597-2620, 1975.

Neukum, G., B. A. Ivanov, and W. K. Hartmann, Cratering records in the inner solar system in relation to the lunar reference system, Space Sci. Rev., 96, 55-86, doi:10.1023/A:1011989004263, 2001.

Neumann, G. A., M. T. Zuber, D. E. Smith, and F. G. Lemoine, The lunar crust: Global structure and signature of major basins, J. Geophys. Res., 101, 16841-16863, doi:10.1029/96JE01246, 1996.

Nyquist, L. E., D. D. Bogard, and C.-Y. Shih, Radiometric chronology of the Moon and Mars, in The Century of Space Science, edited by J. A. Bleeker, J. Geiss, and M. Huber, pp. 1325-1376, Kluwer Academic Publishers, 2001.

Ohtake, M., T. Matsunaga, J. Haruyama, Y. Yokota, T. Morota, C. Honda, Y. Ogawa, M. Torii, H. Miyamoto, T. Arai, N. Hirata, A. Iwasaki, R. Nakamura, T. Hiroi, T. Sugihara, H. Takeda, H. Otake, C. M. Pieters, K. Saiki, K. Kitazato, M. Abe, N. Asada, H. Demura, Y. Yamaguchi, S. Sasaki, S. Kodama, J. Terazono, M. Shirao, Y. Yamaguchi, A. Yamaji, S. Minami, H. Akiyama, and J. L. Jossett, The global distribution of pure anorthosite on the Moon, Nature, 461, 236-241, doi:10.1038/nature08317, 2009.

Pieters, C. M., J. W. Head III, L. Gaddis, B. Jolliff, and M. Duke, Rock types of South Pole-Aitken basin and extent of basaltic volcanism, $J$. Geophys. Res., 106, 28001-28022, doi:10.1029/2000JE001414, 2001.

Pike, R. J., Size-dependence in the shape of fresh impact craters on the Moon, in Impact and Explosion Cratering, edited by D. J. Roddy, R. O. Pepin, and R. B. Merrill, pp. 489-510, Pergamon Press, New York, 1977.

Schultz, P. H. and P. D. Spudis, Evidence for ancient mare volcanism, Proc. Lunar Planet. Sci. Conf. 10th, 2899-2918, 1978.

Schultz, P. H. and P. D. Spudis, Beginning and end of lunar mare volcanism, Nature, 302, 233-236, doi:10.1038/302233a0, 1983.

Schultz, P. H., C. H. van der Bogert, and C. M. Pieters, The possible generation of friction melts at the lunar crater, Buys-Ballot, Lunar Planet. Sci. XXIX, Abstract \#1863, 1998

Smith, D. E., M. T. Zuber, G. A. Neumann, and F. G. Lemoine, Topography of the Moon from the Clementine LIDAR, J. Geophys. Res., 102, 15911611, doi:10.1029/96JE02940, 1997.

Solomon, S. C., Mare volcanism and crustal structure, Proc. Lunar Sci. Conf. 6th, 1021-1042, 1975.

Spudis, P. D., R. A. Reisse, and J. J. Gillis, Ancient multiring basins on the Moon revealed by Clementine laser altimetry, Science, 266, 1848-1851, 1994.

Stöffler, D. and G. Ryder, Stratigraphy and isotope ages of lunar geologic units: chronological standard for the inner solar system, Space Sci.Rev., 96, 9-54, doi:10.1023/A:1011937020193, 2001.

Stuart-Alexander, D. E., Geologic map of the central far side of the Moon, Map I-1047, U.S. Geol. Surv. Prof. Pap., Washington, D. C., 1978.

Taylor, L. A., J. W. Shervais, R. H. Hunter, C.-Y. Shih, B. M. Bansal, J. Wooden, L. E. Nyquist, and L. C. Laul, Pre-4.2 AE mare basalt volcanism in the lunar highlands, Earth Planet. Sci. Lett., 66, 33-47, doi:10.1016/0012-821X(83)90124-3, 1983.

Terada, K., M. Anand, A. K. Sokol, A. Bischoff, and Y. Sano, Cryptomare magmatism 4.35 Gyr ago recorded in lunar meteorite Kalahari 009, Nature, 450, 849-853, doi:10.1038/nature06356, 2007.

Wagner, R., J. W. Head III, U. Wolf, and G. Neukum, Stratigraphic sequence and ages of volcanic units in the Gruithuisen region of the Moon, J. Geophys. Res., 107, doi:10.1029/2002JE001844, 2002.

Wasson, J. T. and P. H. Warren, Contribution of the mantle to the lunar asymmetry, Icarus, 44, 752-771, doi:10.1016/0019-1035(80)90142-6, 1980.

Werner, C. L. and D. E. Loper, On lunar asymmetries: 2. Origin and distribution of mare basalts and mascons, J. Geophys. Res., 107, 10.1029/2000JE001442, 2002

Werner, S. C., B. A. Ivanov, and G. Neukum, Theoretical analysis of secondary cratering on Mars and an image-based study on the Cerberus Plains, Icarus, 200, 406-417, doi:10.1016/j.icarus.2008.10.011, 2009.

Wieczorek, M. A. and R. J. Phillips, Potential anomalies on a sphere: applications to the thickness of the lunar crust, J. Geophys. Res., $\mathbf{1 0 3}$ 1715-1724, doi:10.1029/97JE03136, 1998.

Wilhelms, D. E., The geologic history of the Moon, U.S. Geol. Surv. Prof. Pap. 1348, 302 pp, 1987.

Wilhelms, D. E. and J. F. McCauley, Geological map of the near side of the Moon, Map I-703, U.S. Geol. Surv. Prof. Pap., 1971.

Zhong, S., E. M. Parmentier, and M. T. Zuber, A dynamic origin for the global asymmetry of lunar mare basalts, Earth Planet. Sci. Lett., 177, 131-140, doi:10.1016/S0012-821X(00)00041-8, 2000.

T. Morota (e-mail: morota@planeta.sci.isas.jaxa.jp), J. Haruyama, M Ohtake, T. Matsunaga, T. Kawamura, Y. Yokota, C. Honda, J. Kimura, N. Hirata, H. Demura, A. Iwasaki, T. Sugihara, and LISM Working Group 